\title{
Outbreaks of thrush in pigeons in Punjab State of India
}

\author{
Madhav Mugale • Abid Ali Bhat • D. S. Gavhane • \\ Sartaj Ahmad Bhat
}

Received: 23 November 2013 / Accepted: 3 June 2014 / Published online: 8 July 2014

(C) The Author(s) 2014. This article is published with open access at Springerlink.com

\begin{abstract}
Due to high monetary turnover in business, white pigeon keeping for game purposes is gaining more popularity in Punjab. Overcrowding and poor management by undertrained naive farmers make these birds more susceptible to diseases not known so far in this region. A farmer reported that about a hundred pigeons were unable to feed properly and regurgitate feed. Birds lost body condition gradually, and three among these died. Both alive and dead pigeons were presented to the Veterinary Clinical Complex (VCC) for detailed examination. All these pigeons were found to be cachectic with wasting of breast muscles. On necropsy, no significant gross lesions were recorded in most of the visceral organs, except mottling of the liver. However, in the oral cavity, gray Turkish towel-like lesions were seen at the opening of the pharynx which continued into the larynx and proximal esophagus. Microscopic examination of material scrapped from lesions revealed a large number of budding yeast-like organisms and pseudohyphae, suggestive of Candida spp. Histologically, marked necrosis and sloughing of oral and esophageal mucosal epithelium with the presence of pyogranulomatous inflammation containing a large number of Candida organism were observed. To the authors' knowledge, there seems to be no outbreak of thrush in pigeons in Punjab previously.
\end{abstract}

Keywords Candidiasis · Cytology · Histopathology · Pigeons $\cdot$ Thrush

M. Mugale $(\bowtie) \cdot$ A. A. Bhat $\cdot$ D. S. Gavhane $\cdot$ S. A. Bhat Teaching Veterinary Clinical Complex, Khalsa College of Veterinary and Animal Sciences, Amritsar, Punjab, India

e-mail: madhav.mugale@gmail.com

\section{Introduction}

Candidiasis is an occasional opportunistic fungal disease of importance in poultry. It has also been reported to be a disease or an intestinal infection in numerous species of wild birds that are being raised in captivity (Milton 1999). The disease is sporadic in nature, and outbreaks occur where proper management protocols are not followed. Candida albicans $(C$. albicans), a yeast-like fungus, is the primary cause of candidiasis. C. albicans is a common environmental organism and an opportunistic pathogen having normal inhabitant of the avian crop. Candidiasis has been observed in chickens, pigeons, turkeys, geese, guinea fowl, pheasants, quail, parrots, and other birds (Moretti et al. 2000). Ingestion of contaminated food or drinking water is the usual means for its transmission. Contaminated environments, such as litter from poultry and game bird rearing facilities, refuse disposal areas, discharge sites for poultry operations, and areas contaminated with human waste are suggested as sources for Candida exposure for birds. Impacted food, beak abnormalities, and tongue injuries predispose the bird to oral candidiasis. Young birds with crop stasis are especially more susceptible to this disease (Bauck 1994; Kunkle 2003).

The natural mode of feeding for nestling pigeons is by thrusting their soft, pliable beak into the parent's gullet to drink crop milk secreted from the lining epithelium of the crop (Tottenham 1982); therefore, candida organisms can be transmitted from infected parents to their nestlings through crop milk. Candidiasis is almost always secondary to other diseases or due to the immunosuppression or after prolonged antibiotic therapy. In birds, particularly, the stress of heavy flight or force racing or force feeding (Tsat et al. 1994) may cause oral or gastrointestinal candidiasis. If not treated on proper time, this may lead to mortality. This disease has tremendous zoonotic importance for humans. The present manuscript describes the 
outbreaks of oral candidiasis, its diagnosis, pathological features, and therapeutic management.

\section{Case description}

Two outbreaks were reported near Ludhiana District, Punjab, of about 120 and 250 white game pigeons each. The affected pigeons suffered from inappetence, anorexia, and regurgitating feed. Bird's feather quality became poor and unkempt. Among the affected birds, a few were reported of having diarrhea. The affected birds lost their body condition gradually and became cachectic with wasting of breast muscles. In the first and second outbreaks, three and two pigeons died, respectively. The representative live and dead pigeons were presented to investigate the cause. History taken from owner was noted. The dead birds were subjected to necropsy.

At necropsy, no significant gross lesions were recorded in most visceral organs, except the liver. The liver showed mottling. Thickening of the crop mucosae were noted. However, on opening the oral cavity, gray towel-like lesions at the opening of the pharynx and larynx were seen, and this yellowish white pseudomembrane on the mucosa continued into the proximal esophagus (Fig. 1). Impression smears were made from lesions of oral and esophageal mucosa. Suitable pieces of tissue were collected in $10 \%$ neutral buffered formalin and subjected to routine histopathological examination.

Cytological examination impression smears stained by Leishman's stain revealed a large number of budding yeastlike organisms and early pseudohyphae (Fig. 2), suggesting Candida as an etiological agent and, hence, the disease thrush.

Histopathologically, marked necrosis and hyperkeratosis of oral and esophageal mucosa were observed. Erosion and ulcerations along with the presence of mild pyogranulomatous inflammation containing a large number of Candida

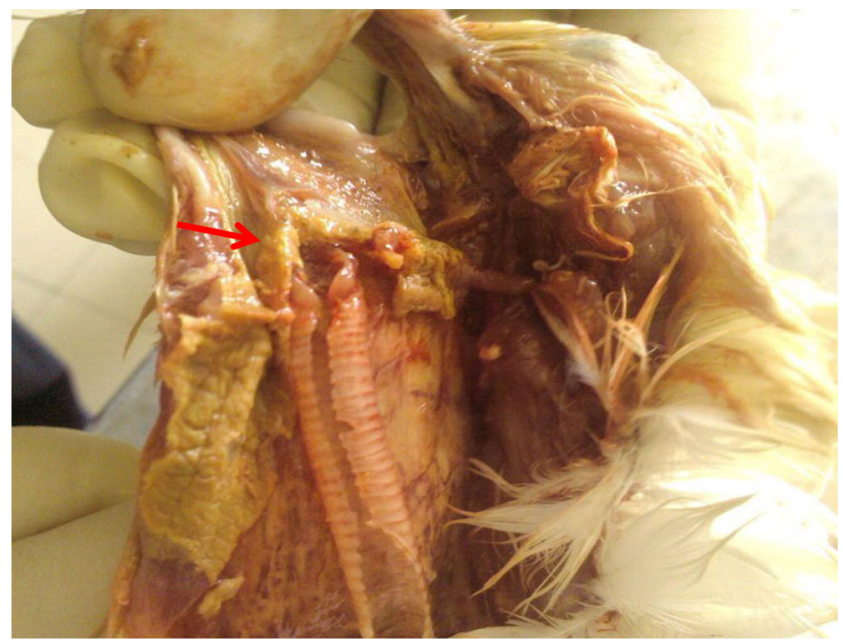

Fig. 1 Pseudomembrane on esophagus, pharynx, and larynx (red arrow)

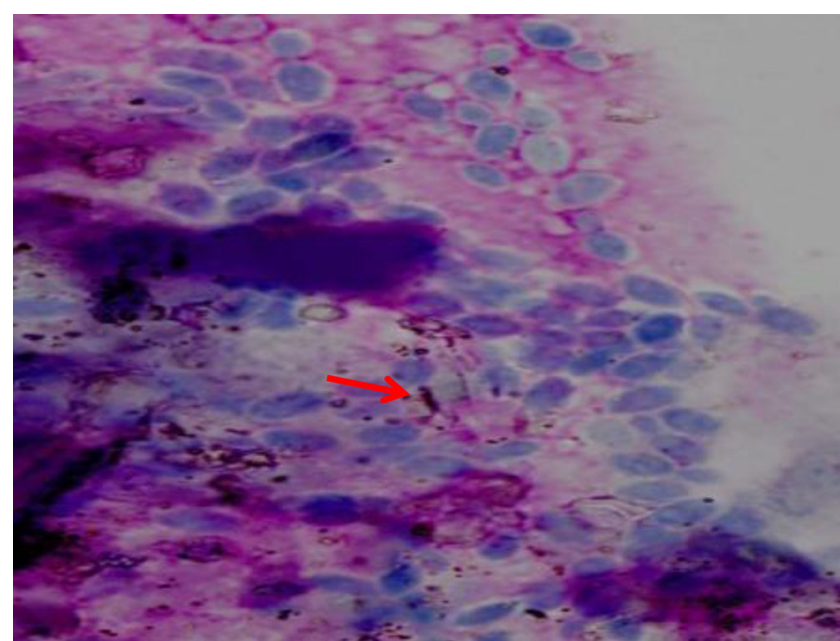

Fig. 2 Large number of yeast-like organisms and early pseudohyphae (red arrow)

organisms were observed in the oral and esophageal mucosa (Figs. 3 and $4 \mathrm{a}, \mathrm{b}$ ).

On the basis of gross and histopathological features, the disease was diagnosed as oral candidiasis, i.e., thrush.

All the affected birds from the farm were treated with copper sulfate at $2 \mathrm{~g} / \mathrm{l}$ of water for 15 days. Farmers were suggested oral application of candid lotion to the affected birds, which showed dramatic recovery from the infection.

\section{Discussion}

C. albicans is a saprophytic fungus and commensal of the upper avian digestive tract (Bauck 1994). It can be readily isolated from the intestine and mucocutaneous surfaces of birds, animals, and humans. Pathology due to infection is an

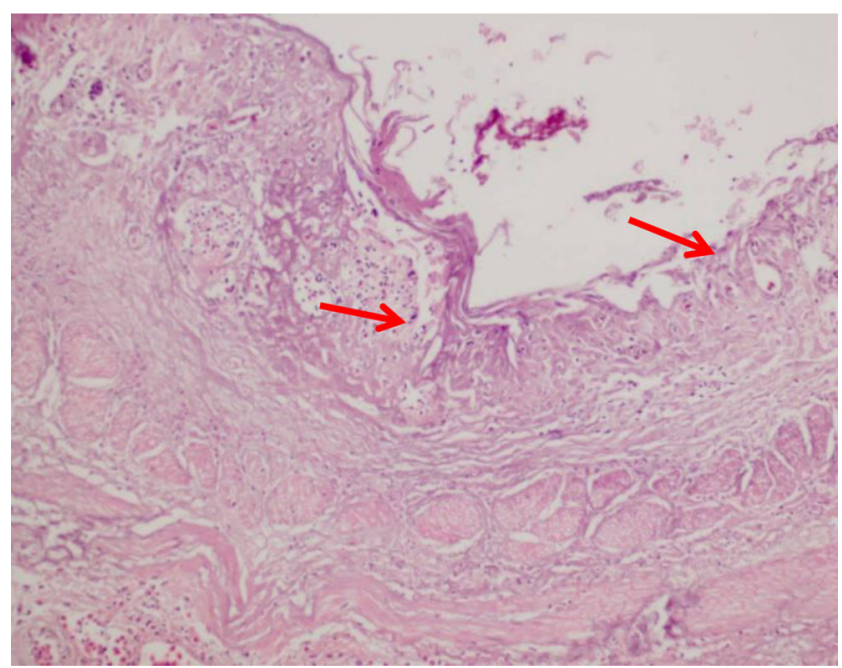

Fig. 3 Section of esophagus showing marked sloughing of epithelium and inflammation (red arrow) 
aberration brought on by a lapse of immunologic homeostasis or shifts in the ecology of microflora colonizing the host (Kunkle 2003). Increased virulence of the fungus plays a vital role in establishing the disease (Chute 2001). Litter from poultry houses and game bird areas, waste, and disposal areas contaminated with human waste are suggested as potential sources for exposure to Candida introduction (Bauck 1994; Oglesbee 1997). The risk factors, which predispose to candidiasis and aggravate disease, include malnutrition, vitamin D deficiency, poor hygiene, prolonged use of antibiotic causing suppression of normal bacterial flora, and stress leading to immunosuppressive diseases (Velasko 2000). In the present case, gross examination revealed gray towel-like lesions at the opening of the pharynx and larynx, which has also been reported by many workers (Schmidt et al. 2003; Velasko 2000; Bauck 1994). On histopathological examination, extensive tissue damage of the upper digestive tract was observed. This damage might be due to various recognized virulence factors of $C$. albicans such as adhesins having affinity for
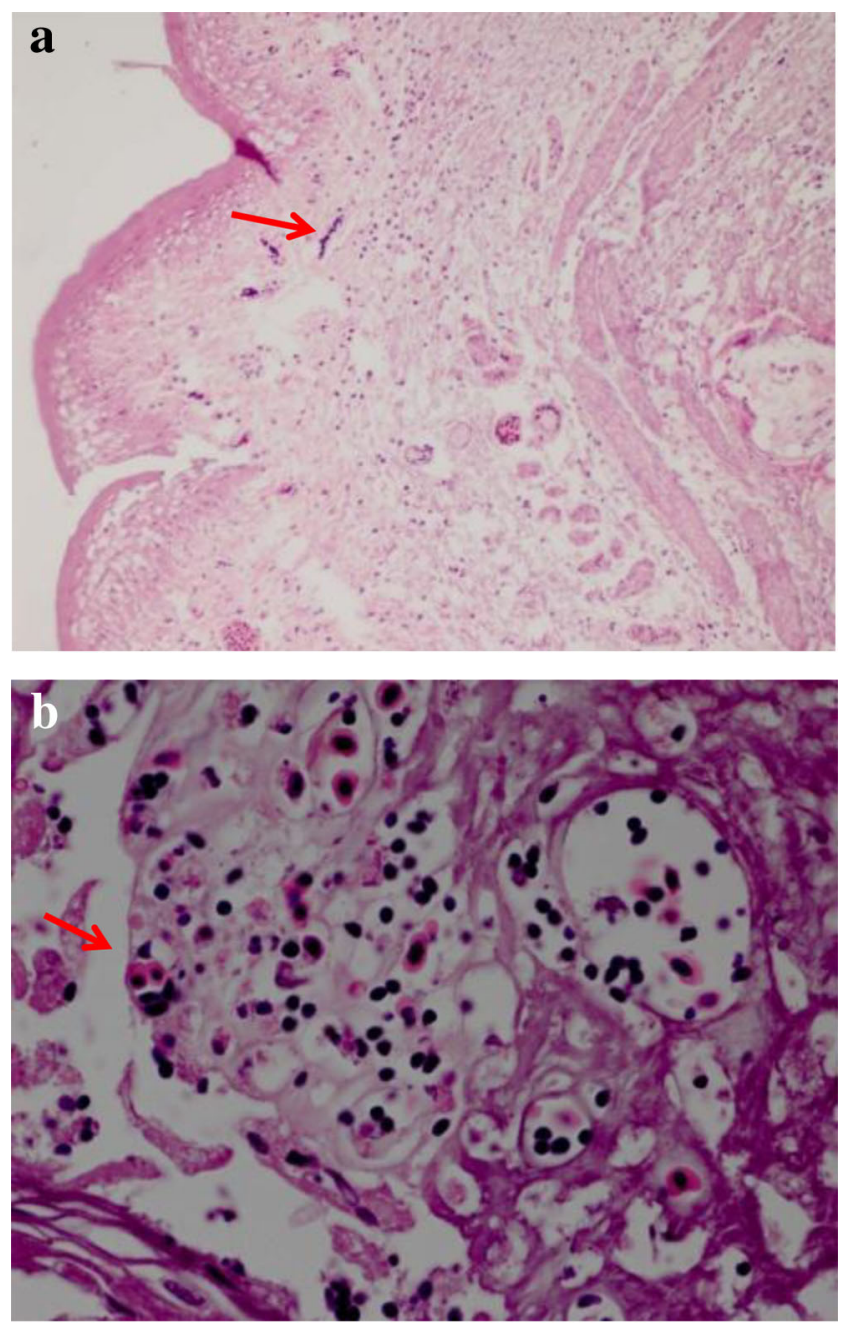

Fig. 4 a Section of esophagus showing hyperkeratosis and candida organism (red arrow, $\times 10$ ). b Higher magnification of a showing division of and candida organism (red arrow, $\mathrm{H} \& \mathrm{E}, \times 40$ ) fibronectin on the cell surfaces and phospholipase present on hyphal tips enhancing invasiveness and yeast forms causing tissue damage (Macdonald 1984; Ruchel 1984). C. albicans can produce proteinases by which keratin and collagenase are lysed (Hattori et al. 1984; Negi et al. 1984). The presence of hyperkeratosis in the birds might partially be due to mechanical irritation by the impacted food. Endotoxin produced by $C$. albicans might have played a role in the development of hyperkeratotic lesions (Tsai et al. 1992; Ruchel 1984). Classically, this disease is associated with either vitamin A deficiency or prolonged antibiotic administration. The source of candida infection in the present outbreaks could not be ascertained. However, the crop milk supplied by the parents might be one of the several reasons. The lack of antibody such as IgA and a high content of carbohydrates in the crop might have favored the establishment of candidial infection. In Punjab, there is a trend among farmers, i.e., self-treatment in animals as well as in avian species, particularly with antibiotics which are easily available; hence, their prolonged use might have favored the establishment of candida infection in these pigeons. Lack of knowledge, overcrowding, and poor management by undertrained naive farmers are other major precipitating factors.

\section{Conclusion}

The source of infection in the present outbreak could not be ascertained. However, there are many factors which play a role in the development of candidiasis. All these factors deserve further study in relation to this fungal infection in young pigeons.

Open Access This article is distributed under the terms of the Creative Commons Attribution License which permits any use, distribution, and reproduction in any medium, provided the original author(s) and the source are credited.

\section{References}

Bauck L (1994) Mycoses. In: Ritchie BW, Harrison GJ, Harrison LR (eds) Avian medicine: principles and application, 1st edn. Wingers Publishing, Lake Worth, p 1005

Chute HL (2001) Thrush (mycosis of the digestive tract). In: Calnek BW, Barnes HJ, Beard CW, Reid WM, Yoder HW Jr (eds) Diseases of poultry, 10th edn. Iowa State University Press, Ames, pp 360-370

Hattori MK, Yoshiura NM, Ogawa H (1984) Keratinolytic proteinase produced by Candida albicans. Sabouraudia 22:175-183

Kunkle RA (2003) Fungal infections. In: Saif YM, Barnes HJ, Glisson JR, Fadly AM, McDougald LR, Swayne DE (eds) Diseases of poultry, 11th edn. Iowa State Press, Ames, p 901

Macdonald F (1984) Secretion of inducible proteinase by pathogenic Candida species. Sabouraudia 22:79-82 
Milton F (1999) Candidiasis. In: Milton F and Franson, JC (ed.) Field manual of wildlife diseases (1st Ed.). U. S. Department of interior. U. S. Geological Survey, pp 135-36

Moretti AD, Piergili FL, Boncio P, Pasquali ED, Rossi (2000) Isolation of Candida rugosa from turkeys. J Vet Med B 47:433-439

NegI M, Tsuboi R, Matsui T, Ogawa H (1984) Isolation and characterization of proteinase from Candida albicans. J Investig Dermatol 83:32-36

Oglesbee BL (1997) Mycotic diseases. In: Altman RB (ed) Avian medicine and surgery, 1st edn. W. B. Saunders Company, Philadelphia, pp 323-361

Ruchel R (1984) A variety of Candida proteinases and their possible targets of proteolytic attack in the host. Int J Microbiol Hyg A Med Microbiol Infect 257:266-274
Schmidt RE, Reavill DR, Phalen DN (2003) Pathology of pet and aviary birds, 1st edn. Blackwell Publishing Company, New York, p 234

Tottenham K (1982) Orphan birds. In: Petrak ML (ed) Diseases of cage and aviary birds, 2nd edn. Lea \& Febiger, Philadelphia, pp 250-255

Tsai SS, Park JH, Hirai K, Itakura C (1992) Aspergillosis and candidiasis in psittacine and passeriforme birds with particular reference to nasal lesions. Avian Pathol 21:699-709

Tsat SS, Yeh WS, Chi YG, Itakura C (1994) Force-feeding and candidiasis in pigeons. Avian Pathol 23:569-574

Velasko MC (2000) Candidiasis and cryptococcosis in birds. Semin Avian Exotic Pet Med 9:75-81 